Mezhep Araştırmaları Dergisi $\quad$ 12, sy. 2 (Güz 2019): 863-871
Journal of Islamic Sects Research $\quad 12$, no. 2 (Fall 2019):863-871

\title{
MODERN İRAN'DA SIYYASAL VE SOSYAL DÖNÜŞÜMLER
}

Necef Lekzâyî

Visal Yayınları, Çev. Ahmet Çelik ve Saman Barghi, İstanbul 2019, 415 sayfa.

\section{Ahmet ÇIRAKOĞLU*}

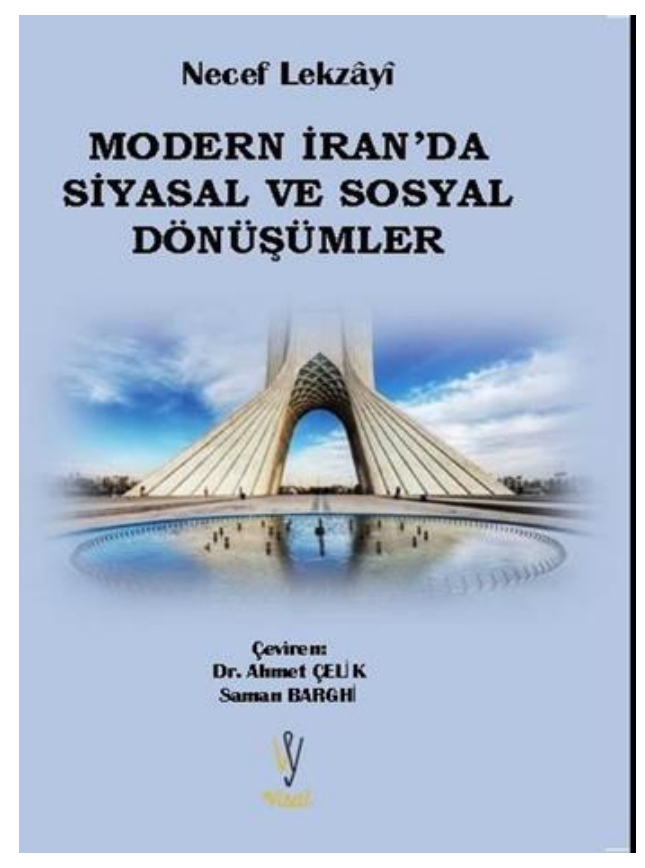

Şiî siyasal düşüncesindeki devamlılığın bir ürünü olan 1979 Devrimi, ulusal düzeyde siyasal ve toplumsal dönüşümleri zaruri k1larken, uluslararası alanda da İslam uygarlığının tarih boyunca var olageldiği itibarını tekrar kazandırmayı şiar edinmiştir. Yillar boyunca geleneksel din ile pozitif bilimler arasında yaşanan kopukluk, bu konuda din adamlarının yaşadığ1 en büyük engel olmuştur. İslam dünyasının içerisinde bulunduğu geri kalmışlığın tetkiki ve çözümü, ilmin 1şığında gelissen fikrî açılımlarla mümkün olacaktır. Geleneksel İslamî görüşlerin yanında, bu fikirlere modern dünyada var olan yeni bilimlerin desteğiyle eleştirel açılımlar getiren eser, sorunun ilmî yollarla aşılmasına katkı vermeyi amaçlamaktadır. Kitabın yazarı olan Hüccetü'l-İslam Necef Lekzâyî, Dünya Ehli Beyt Kurultayı kültür

Yüksek lisans mezunu | ORCID ID: orcid.org/0000-0001-5491-1780 / eposta: irday.geruri@gmail.com.

\begin{tabular}{ccc}
\hline Başvuru|Submission & Kabul|Accept & Yayın|Publish \\
31.07.2019 & 21.11 .2019 & 31.12 .2019 \\
\hline DOI & $10.18403 /$ emakalat.599105
\end{tabular}


işleri daire başkanı ve aynı zamanda genel sekreter danışmanıdır. İran'da yaşanan dönüşümlerin din adamlığ vasfının yanında siyaset bilimi doktoru da olan bir ilim adamının gözünden teorik yaklaşımlar ve bilimsel değerlendirmelerle okuyucuya sunulması, kitabın değerlendirmek üzere seçilmesinde ana etken olmuştur. Olayların odak noktasına dinin ve din adamlarının yerleştirilmesi kitabın okuyucu kitlesini belirliyor olsa da, söz konusu eser günümüz İran'ını oluşturan fikri yaklaşımların anlamlandırılabilmesi açısından tüm kesimlerin ilgisine açıktır. Kitabın kapak resminde Pers İmparatorluğu'nun 2500. yılı anısına devrimden önce inşa edilen Azadi Kulesi'nin kullanılması, İran tarihindeki sürekliliğin yazar tarafından da benimsendiğini göstermektedir.

"Modern İran” kavramı ve kapsadığı dönem, İran'ın farklı toplumsal kesimleri arasında daima tartışma konusu olmuştur. Uzun yıllardan beri geleneksel toplum içerisinde Batı tarzı modernleşmeye karş1 katı bir muhalefet yerleşmiştir. İslam Cumhuriyeti resmi söylemde (modernleşme teorilerinin dayattığı) modernleşmenin kendisine bile karşı çıkarken, muhalif kesim Kaçarlar döneminde eğitim amacıyla Avrupa'ya ilk öğrencilerin gönderilmesiyle başlayan modernleşme dönemini Pehlevi Hanedanlığı'nın yıkılışıyla sonlandırmaktadır. Muhalifler teokratik oligarşi olarak tanımadıkları İslam Cumhuriyeti'ni modern İran tarihini akamete uğratan dönem olarak tasvir ederken, mevcut yönetim yanlıları ise yabancı güçlere dayalı sultanî diktatörlük şeklide nitelendirdikleri Pehleviler dönemini kendi modernlik tanımlarının dışında tutarlar. 1979 Devrimi'yle dünyada benzeri olmayan bir devlet yönetimin hayata geçirilmesi, Batı tarzı modernleşmeye karşı gelişen olumsuz tavrı açıklayabilir. Devrimciler yönetim tarzlarını ve sosyo-politik dönüşümleri Batılı kavramlarla açıklamaktan kaçınmakta, buna alternatif kavramsal dil kullanmaya özen göstermektedirler. Yazar ise modern İran tarihinin başlangıcı hakkındaki görüşleri Safeviler, Kaçarlar ve Meşrutiyet Dönemi olarak gruplandırdıktan sonra, bunu Safeviler dönemiyle ele almanın daha gerçekçi olacağını dile getirmektedir. Eser boyunca, Kaçarlar dönemi için "Eski İran", Kaçarlar sonrası için ise "Yeni İran" kavramı kullanılmıştır. 
Lekzâyî'nin bu eseri; kavramsal açıklamalar, modellemeler, teorik çerçeve, soru-cevap gibi sistematik bir düzlem ihtiva etmesi hasebiyle kapsamlı bir akademik tez hüviyetindir. Ki yazar da bu eserin bilimsel yaklaşımla İran'in modern siyasi tarihi, sosyo-politik dönüşümleri ve İran Devrimi'yle ilgili verilecek olan derslerde yardımc kaynak olarak faydalanılması gereken ders kitabı olarak hazırlandığını belirtmektedir. İran'da yaşanan dönüşümlerde dinin rolüne ağırlık verilmesi, yazarın fikrî yöneliminin anlaşılması açısından önemlidir. Yazar, Yeni İran'ın oluşumunda rol oynayan olaylar, değişimler ve dönüşümlerin incelendiği bu çalışmasından beklentisini, dini ve siyasi kültürün gelişmesi ve bu sayede İslam siyasi düşüncesinin tüm dünyaya yayılması olarak dile getirmektedir. Eseri emsallerinden farklı kılan en belirgin özellik, eserin bütününe hâkim olan fikrî yaklaşımdır.

Kitabın diğer bir önemli özelliği, bilimsel bilgilerin teorik yaklaşımlara dayandırılarak veriliyor olmasıdır. Toplamda dokuz bölümden oluşan kitabın ilk bölümlerinde kavramsal tanımlamalar ve teorik açıklamalar yoğunluktadır. Sonrasında ise konuların mahiyetine göre uzmanların görüssleri yansıtılarak detaylı açıklamalar yapılmaktadır. Kitap özellikle İslam Cumhuriyeti'nin kuruluşunda rol oynayan ilim adamlarının görüşlerini yansıtması bakımından önemlidir. Dini yönüne ağırlık verdiği olayları ilim adamı hüviyetiyle değerlendiren yazarın, alan yazına hâkim olduğu açıkça görülmektedir. Yerli ve yabancı birçok kaynağın kullanıldığı bu çalışma, çeviride tamamına yer verilemeyen oldukça geniş bir literatürü içermektedir.

Yazar, giriş bölümüne araştırmanın genel çerçevesinin çizilmesiyle başlar ve birinci bölümde konuyla ilgili detaylı kavramsal tanımlamalar yaparak kuramsal çerçeveyi okuyucuyla paylaşır. İran'in tarih boyunca yaşadığı sosyal ve politik dönüşümleri bilgi, konu, kalkınma, güç ve ayrışma odaklı çerçeveden yararlanarak ele alır. Kavramsal olarak "Modern İran" kavramı ve politik, ekonomik, kültürel alanda farklılaştırılan "Eski/Geleneksel İran" ve "Yeni/Modern İran" kavramına açıklık getiren yazar, "dönüşüm" ve muadili kavramlar arasındaki ince ayrımı okuyucuyla paylaşarak bu kavrama net bir tanımlama getirir. Aynı zamanda İran'ın son iki yüz yılında yaşanan İran-Rus 
Savaşları, Tütün Hareketi, Meşrutiyet Devrimi, Petrolün Millileştirilmesi, Ak Devrim ve 1979 Devrimi gibi temel dönüşümlerin, İran tarihinde bir çözülme mi, yoksa süreklilik mi olduğu, geleneksellik ile modernite arasında bir karşıtlık/çelişki olup olmadığı tartışılmaktadır.

Modern İran'da yaşanan dönüşümler analiz edilirken naklî tarih anlayışı yerine, düşünsel ve yöntemsel bir eğilim tercih edilmiştir. Araştırmanın teorik çerçevesi tarih felsefesi özelinde teorik tarih felsefesine dayanmaktadır. Burada yazarın fikrî yaklaşımını anlamak açısından sorduğu en önemli soru, tarihin hareket ettirici gücünün ne olduğudur. Ra'd Suresi'nin "Bir toplum kendisindekini değiştirmedikçe Allah onlarda bulunanı değiştirmez" (s. 28) ayeti 1şığında Kur'an-1 Kerim’in öğretilerini izlediğini söyleyen yazara göre tarihin temel hareket ettiricisi, insanların batınî (duygu, bilgi, değer, içgüdü, karakter vb.) muhtevasıdır. Kültürel kuramlar arasında yer alan bu görüşe göre, insan davranışlarındaki değişim ve dönüşüm toplumsal hareketliliğin de yönlendiricisi konumundadır. Bu minvalde din adamları, devlet yöneticileri, aydınlar, yabancı güçler ve bu dörtlü arasındaki ilişki, modern İran'da yaşanan sosyal ve politik dönüşümlerin itici gücünü oluşturmaktadır. Kitaptaki tartışmaların odağı da, dörtlü güçler ekseninde İran'daki dönüşümlerin ve bu güçlerin İran'in geri kalmışlığı/ilerlemesi konusundaki etkilerinin akademik hassasiyetle analiz edilmesidir.

Kavramsal tanımlamalarla başlayan ikinci bölümde, geçmişten günümüze İran'da devletin mahiyeti; yönetim modellerine kişi odaklı bakan "Weberci kuram" ve üretim ilişkileri üzerinden değerlendiren "Marksçı kuram", Immanuel Wallerstein'in "dünya sistemleri kuramı”, Kaztuziyan'ın “İran’a özgü diktatörlük teorisi”, Skechel'in "rantiyer devlet teorisi", John Foran'in "kırılgan direniş teorisi" ve son olarak da Müslüman filozofların, kelamciların, fakihlerin görüşleri ışığında ulemanın yaklaşımıyla açıklanmaya çalışılmıştır. Modern İran'da Kaçar Hanedanlığı'nın yönetim sistemi (Doğulu gelenekçi) patrimonyalizm, Pehlevi Hanedanllğınınki ise (Doğulu gelenekçi) neo-patrimonyalizmdir, bazı analistlerin gelenekçi ve değersel model olarak gördüğü İslam Cumhuriyeti'nde ise yönetim karizmaya dayanmaktadır. Yapılan değerlendirmelerin sonucunda İran'da hâkim olan en kötü yönetimin yabancı güçlere 
bağımlı diktatörlük modeli olan Pehlevi Hanedanlığ dönemi, en iyisinin ise İran'a bağımsızlık ve özgürlüğü getiren İslam Cumhuriyeti modeli olduğu kanısına varılır (s. 38).

Devletin mahiyeti konusunda ulemanın görüşlerine değinilen kısımda, aslen kuramsal bağlamda İran Devrimi'nin ve İslam Cumhuriyeti'nin meşruiyet zemini oluşturulmaya çalışılmaktadır. Hz. Ali'nin uygulamaları ve İmam Humeyni'nin İslam Cumhuriyeti'nin temelini oluşturan siyasetinin, Hz. Muhammed'in "dini siyasetin ruhu kılan" sünnetinden alındığı iddia edilmekte, Müslüman siyasi filozofların görüşü doğrultusunda $\mathrm{Hz}$. Muhammed'in, masum imamlardan birinin veya sünnetin önderinin başında yer aldığı "erdemli (ideal) devlet" kavramına atıf yapılarak bu iddia desteklenmeye çalış1lmaktadır. Konuyu "İmamet" paradigmasını merkeze alarak değerlendiren Şiî filozoflara göre de gaybet döneminde sünneti temsil eden, gerekli şartlara haiz fakihin başında olduğu sistem meşrudur. Onlara göre İmamet olduğu için hatm-i nübüvvet ( $\mathrm{Hz}$. Muhammed'in gelişiyle peygamberliğin sona ermesi) bitmiştir, devam eden İmamet'tir (s. 71-72).

Kitabın üçüncü bölümünde ulemanın İran'daki nüfuzu ve din kurumunu korumak amacıyla yapılan çalışmalara ilişkin görüşler üzerinde durulmuştur. Dini güçlerin etkisi sadece Şiîlik mezhebi odağa alınarak işlenmiş, İranlıların Şiîliğe yönelme sebepleri konusunda $\mathrm{Hz}$. Ali ile $\mathrm{Hz}$. Osman taraftarları arasındaki mücadeleden başlanarak bu ayrılığın belirginleşmesine katkı sağlayan tarihi gelişilmelere değinilmiştir. Bu noktada Şiîliğin modern İran'daki siyasal ve toplumsal dönüşümlerin en etkili gücü olduğu savı yazarın önemli iddialarından biridir.

Modern İran tarihindeki iki önemli toplumsal dönüşüm olan Meşrutiyet Hareketi ve İran Devrimi'nin ana destekleyicisi İran'daki dini güçler olmuştur. İslamî ve entelektüel grupların birlikte hareket etmesi ve İngiltere'nin desteğiyle başarıya ulaşan Meşrutiyet Hareketi'nde etkili olan faktörler Şia siyasal kültürü ve politik entelektüel kültürdür. 1979 devrimi ise, Humeyni, Tabâtabâî, Mutahharî, Behiştî gibi İslamî bir hükümet kurularak şah rejiminin devrilmesi amaciyla her alanda aktif mücadeleye odaklanan din adamları ve kısmen de olsa Golpâyegânî, Şerîatmedârî, Maraşî 
Necefî gibi rejimin değişmesine ihtimal vermediğinden dolay1 kişilerin değişmesini yeterli görerek bu doğrultuda toplumsal mücadeleye inanan 1lımlı âlimlerin önderlik ettiği mücadeleler sonucunda gerçekleşmiştir. Yazar, diş güçlerin yönlendirdiği uluslararası sistemin karşısında duran ve bölgedeki küresel yapıyı tersyüz eden İran Devrimi'nin İslamî karakterli bir devrim olduğunu iddia etmektedir.

Dördüncü bölümde yazar, Meşrutiyet ve İslam Cumhuriyeti'nin kuruluşuyla ilgili teorik ilkeleri ve İran'da yaşanan sosyo-politik dönüşümleri özellikle Ayetullah Şeyh Muhammed Huseyn Nâinî ve İmam Humeyni gibi yerli teorisyenlerin fikirleri çerçevesinde irdeler. Fikrî olarak Nâinî ve Humeyni'nin diğer din adamlarından farkı, hükümetin ve siyasi sistemin oluşumunda halkın rolüne ilişkin yeni bir yol çizmeleridir. Bu noktada halkın hükümetteki rolüne özel bir önem veren Humeyni, fakihler için hükümet kurmanın vacib-i kifaye olduğunu, halkın da fakihlere destek vermekle yükümlü olduğunu söylemekte, meşruluk kaynağı bakımından başında masum imamın bulunduğu hükümetin en üstün yönetim şekli olduğunu savunmaktadır. Bunun mümkün olmadığını dile getiren Nâinî ise meşrutiyet rejimine geçilerek toplumsal ve siyasi konuların din adamlarının denetiminde olan parlamentoya devredilmesinin gerekliliğini vurgulamaktadır. Yazara göre İslam peygamberi ve masum imamların kurduğu devletin devamı anlayışını kuramsallaştıran Humeyni'nin Velâyet-i Fakih görüşü, modern devletin anlamını tamamlamaktadır. İlahi temelde kurulan bu modern devlette yönetimin anahtar kavramları ise temsilcilik ve çoğunluktur. İdeal devlet tarzı da, dini öğretilere göre kurulan ve hem ilahi rızayı, hem de halkın katılımını gözeten İslamî devlettir (s. 230-231).

Geri kalmışlık ve kalkınma çabalarının değerlendirildiği beşinci bölümde, üreticilik ve kalkınma; güç ve siyaset, düşünce ve kültür, ekonomi ve servet üçlüsünün bileşeni olarak değerlendirilmektedir. Yazar geri kalmışlık hakkında din karşıtı görüş, (Marksist) solcu görüş, (Batı yanlısı) liberal görüş, Kaçar şahlarının ve İslamî diriliş̧̧ilerin görüşlerini aktardıktan sonra, geri kalmışlığın din karşıt1 uygulamalar ve dincilerin yıllarca mücadele ettiği sömürü düzenine dayalı istibdat rejiminden kaynaklandığı sonucuna varır. 
Kitabın altıncı bölümünde, çatışma, gerginlik, karşıtlık temelli olan ve ikilemler üzerine kurulan "ayrışma teorisi" üzerinden İran'da sosyo-politik ayrışmalar açıklanarak, bu ayrışmaların kimlik politikaları ve siyasal alan üzerindeki etkileri değerlendirilmiştir. Bu ayrışmalar, aynı zamanda siyasal partilerin karakterini ve kimlik tartışmalarını da şekillendirmektedir. Pehleviler döneminde Farsları âri ırk olarak tanımlayarak milliyet kökenine dayandırılan kimlik meselesi, İslam Cumhuriyeti'yle birlikte aslolan İslamî karakterine geri dönmüştür. Din ile devlet arasındaki ilişkinin temeli de "insan ile Allah arasındaki ayrışma" üzerinden değerlendirilir. Bu noktada meşruiyetini ilahi kaynaklara dayandıran İran'ın yönetim yapısı, ayrışmaları sentezleyen bir niteliğe sahiptir. Humeyni'ye göre, din siyasetten daha kapsayıcıdır ve bu sebeple siyaset dinin içinde yer alır, dolayısıyla devlet kurumunun davranışları dini olmalıdır. Din ve siyasetin birbirini tamamlamasıyla ilgili olarak yazar şu tespitte bulunur: 'Dinin ürünü 'meşruiyet' ve hükümetin ürünü 'iktidar'dır. Bu yüzden gücün dine iktidar kazandırabilmesi için dinin yönetime meşruiyet kazandırmas1 gerekir" (s. 283).

Aydınlanma kavramının tarihsel gelişimiyle birlikte ele alınarak tüm yönleriyle açıklandığı yedinci bölümde, İran'ın aydınlanmadan sekülerizme olan yolculuğu konu edilmektedir. Yazara göre aydınlanma, genel anlamıla mevcut düzene eleştirel bakıştan doğmuştur ve bu anlamda düzene muhalif olanlar da aydın olarak tanımlanır. Fakat Humeyni bu özellikleri göstermesine rağmen hiçbir zaman klasik anlamda bir aydın olarak anılmamıştır. İran'da klasik manada aydınlanmanın doğuşu liberal ve sosyalist/Marksist kuşak düzleminde Batı'dakiyle benzer özellikler taşısa da, dini aydınlanmanın kökenlerini Cemâleddîn Efgânî̀ye dayandırmak mümkündür. Yakın tarihte ise bu akım Mehdi Bâzergân, Ali Şerîatî, Celâl Âl-i Ahmed, Abdulkerîm Surûş gibi aydınlar tarafından devam ettirilmiştir.

Yazara göre dini dünyevileştirmeyen bir modernite anlayışını kabul etmek dinden uzaklaşmak anlamına gelmez. Dolayısıyla sekülerleşmek azami düzeyde olmadığı müddetçe de dinle çelişmez. Dini aydın olan birinin, dinin asgarisini kabul etmiş olması gerekir. Bu konuda Surûş'un şu sözleri aktarılır: "Kim demiş ki, sekülerizm kötüdür. Sekülerizm dine karşı çıkmak anlamında değildir. 
Sekülerizm, bizim dünyamızın akıl ve bilimle yönetilmesi, yönetimimizin fikhî değil, ilmî olmasının gerektiği anlamındadır" (s. 323). Bu bakış açısı aslında kitaba ismini veren "Modern İran" kavramını modernleşme teorisiyle şekillenen klasik Batı modernleşmesinden ayırmakta ve kavrama dini bir aç1lım kazandırmaktadır.

Sekizinci bölümde, İran petrolü özelinde kalkınma ve geri kalmışlık parametrelerinden biri olan ekonomik meseleler üzerinde durulur. $\mathrm{Bu}$ konuda yazar İslam'in ekonomiye bakışını sorgulayarak, kapitalist sistemi eleştiren Marks ve kapitalizmi protestan ahlakıyla özdeşleştiren Weber'in tezleri üzerinden yaptığ 1 teorik tartışmalarla kapitalizm ile din arasındaki ilişkiyi irdelemektedir. Sosyalist eğilimli olan Ahmed Eşref, İran'da kapitalizmin gelişmediği ve gelişmesinin de çeşitli gerekçelerle mümkün görülmediği yorumunu yapmakta, Rızâkulî ise gelişememenin sebebini siyasi dönüşümlerin otoriter düzene değil, otoritere muhalefet şeklinde olmasından kaynaklandığını söylemektedir. Bu bölümde üzerinde durulan en önemli konu, modern İran tarihinde belirleyici bir konumda olan petrolün kalkınmadaki rolüdür. Kimilerine göre "siyah altın", bazılarınca da “İran'ın baş belası” olarak adlandırılan petrolün İran'da keşfiyle birlikte ülke Rusya, İngiltere, ABD gibi sömürgeci güçlerin odağ 1 konumuna gelmiştir.

Dokuzuncu ve son bölümde, modern İran'daki dönüşümlerde yabanc1 güçlerin etkileri üzerinde durulur. Safeviler döneminde Osmanlı Devleti'yle olan mücadelelerle başlayarak, Pehleviler dönemindeki ABD emperyalizminin 1979 Devrimi'yle sona ermesine kadar kesintisiz olarak İran'da varlık gösteren yabancı güçler, modern İran tarihindeki sosyal ve siyasi dönüşümleri şekillendiren ana unsur olmuştur. Günümüzde yabanc1 güçlerin etkisine karş1 direnç gösteren İslam Cumhuriyeti, ABD başta olmak üzere birçok güçlü devletin orantısız yaptırımlarına maruz kalmaktadır. Bu konuda devrim sonrası politikaların Amerikalıları aşağıladığını iddia eden yazar, "ne Doğu, ne Batı" politikasıyla zafere ulaşan devrimden sonra Nojeh Darbesi'nde de başarısız olan ABD'nin artık İran'ın politikalarını şekillendiremeyeceğini, herhangi bir devletin içişlerine müdahalesinin ise İran tarafından kabul edilmeyeceğini dile 
getirmektedir.

Sonuç olarak bu kitap, modern İran tarihi olarak nitelendirilen dönemlerin kritik evrelerini geniş bir çerçeve çizerek, dini kesime yoğun atıflar yaparak aşama aşama okuyucuya aktarmaktadır. Konuların bütün detaylarıyla açıklanabilmesi ve okuyucu tarafından anlaşılabilmesi için akıcı bir dil kullanılmış, kitap bölümlerinin sıralı bir şekilde tasnifine özen gösterilmiştir. Her bölümün başlangıcında konuyla ilgili temel kavramların verilmesi ve kuramsal açıklamaların yapılması kitabın bilimsel yönünü güçlendirmekte, yazar tezlerini bu teoriler çerçevesinde güçlü bir şekilde tartışmaktadır. Kitapta Humeyni başta olmak üzere, Kaçarlar döneminden itibaren modern İran'ın şekillenmesinde rol oynayan, Pehlevi monarşisine direnen ve 1979 Devrimi'nde etkin olan önemli din adamlarının hayatları, görüşleri, mücadeleleri ve önemli eserlerinden etraflica bahsedilmekte, Humeyni'nin bu ulemalar hakkındaki görüşleri aktarılmaktadır. Bu açıdan kitap, yaşanan sosyal ve siyasi dönüşümlerde büyük din adamlarının ve özellikle de devrim lideri Humeyni'nin rolünü odağa almakta, modern İran'ın oluşumunu ulemanın mücadeleleri ve çalışmalarının bir neticesi olarak yansıtmaktadır. İslami ilimler ile pozitif bilimleri başarılı bir şekilde sentezleyen bu eser, alanında literatüre katkı sunacak olan önemli bir çalışma niteliğindedir. 
